\title{
New format for the Journal
}

\author{
Richard D. Weisel, MD
}

\footnotetext{
From the Division of Cardiovascular Surgery, Toronto General Hospital, Research Institute and the University of Toronto, Toronto, Ontario, Canada.

Disclosure: Author has nothing to disclose with regard to commercial support.

Address for reprints: Richard D. Weisel, MD, Division of Cardiovascular Surgery, Toronto General Hospital,

Research Institute and the University of Toronto, 200 Elizabeth St 4N-476, Toronto, Ontario M5G 2C4, Canada

(E-mail: rweisel@uhnresearch.ca).

J Thorac Cardiovasc Surg 2017;153:1

$0022-5223 / \$ 36.00$

Copyright (c) 2016 by The American Association for Thoracic Surgery

http://dx.doi.org/10.1016/j.jtcvs.2016.11.001
}

With the January issue, the Journal provides a new format to organize our material to meet the interests of our readers. We have divided the issue into the 3 major subdivisions: Acquired, Congenital, and Thoracic. Each subdivision is then divided into subsections grouping articles in the same subject. This new format permits the reader to identify all the material available for their interests in one area of the Journal. The result is that some subspecialties may find articles in multiple areas such as Perioperative Medicine, Evolving Technology, Basic Science, and Education. However, these papers will be available in their primary area of interest instead of in a separate section as in the past.

In discussions with our editors and readers, they indicated that they wanted to have all the material relevant to their subspecialty in one place in the Journal. They would then be able to quickly scan that section to decide what to read in greater depth. Although they frequently reviewed the other sections of the Journal, they wanted the material of interest to their expertise consolidated.

The Journal will also provide online collections organized in a similar fashion to provide the contributions

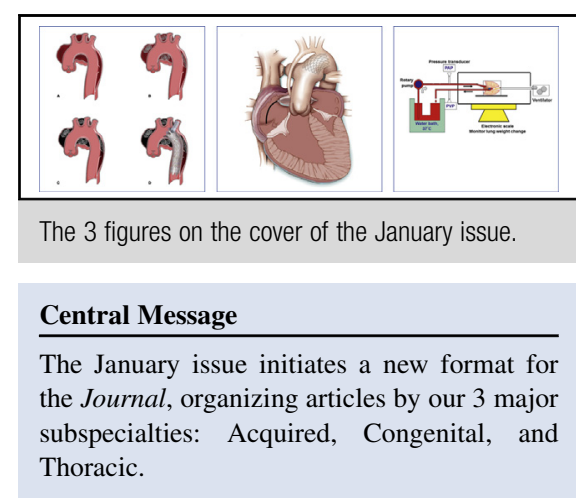

for each subspecialty grouped together. The collections will include published material from the past 2 years (and all material going forward), as well as the articles in press. In addition, we will include material published in Seminars in Thoracic and Cardiovascular Surgery, Operative Techniques in Thoracic and Cardiovascular Surgery, and Seminars in Thoracic \& Cardiovascular Surgery: Pediatric Cardiac Surgery Annual in the collections to enhance their value. The online collections will be live by February.

Finally, the Journal will have a new color template that we hope will facilitate reading our articles, particularly the tables and figures. These enhancements meet our commitment to provide the material thoracic surgeons want in the format they will appreciate. 